\title{
ANALISIS EKONOMI USAHA TANAMAN PANGAN DAN KAMBING KOSTA DI KECAMATAN CARITA KABUPATEN PANDEGLANG, BANTEN
}

\section{ECONOMIC ANALYSIS OF INTEGRATED CROPS AND COSTA GOAT IN CARITA PANDEGLANG BANTEN DISTRICT}

\author{
Supardi Rusdiana* dan Endang Sutedi \\ Balai Penelitian Ternak Ciawi-Bogor, Bogor, 16002
}

Submitted: 30 August 2016, Accepted: 30 September 2016

\section{INTISARI}

Tujuan penelitian ini adalah untuk mengetahui analisis ekonomi usaha tanaman pangan dan kambing Kosta. Penelitian dilakukan di Desa Sukarame Kecamatan Carita Kabupaten Pandeglang Banten. Pengambilan sampel sebanyak 20 responden peternak pada agroekosistem tanaman pangan dan peternak kambing Kosta melalui wawancara langsung dilengkapi alat kuesioner. Data yang digunakan berupa data primer yang diperoleh dari hasil wawancara pada unit rumah tangga peternak,sedangkan data sekunder diperoleh dari Dinas terkait. Analisis data secara deskriptif ,kualitatif, kuantitatif dan analisis ekonomi. Hasil penelitian menunjukkan bahwa usaha tanaman jagung mendatangkan keuntungan bersih Rp559.450,-/panen dengan B/C ratio 1,2. Keuntungan bersih dari usaha kambing Kosta sebesar Rp1.810.950,-/tahun, atau setara dengan Rp248.550,-/bulan dengan B/C ratio sebesar 1,1. Jumlah penyerapan tenaga kerja untuk usaha tanaman jagung sebanyak 131,12 HOK atau setara dengan Rp1.966.800,-/tahun, waktu yang banyak digunakan peternak untuk menanam jagung adalah mengolah lahan dan membersihkan rumput, sedangkan penyerapan tenaga kerja usaha kambing Kosta sebesar 2,57 HOK atau setara dengan Rp38.550,-/tahun, dan waktu digunakan peternak untuk menggembala ternak Limbah hasil pertanian di lokasi penelitian seperti limbah jagung dapat dimanfaatkan sebagai pakan kambing Kosta.

(Kata kunci: Analisis ekonomi, Kambing Kosta, Tanaman pangan)

\section{ABSTRACT}

The purpose of this research was to determine the economic analysis of crop and livestock enterprises Costa goat. The experiment was conducted in the village of Sukarame District of Pandeglang Banten Carita. Interviews to 20 farmers the agro-ecosystem crops and livestock farmer Costa goat using questionnaires. Primary data obtained from interviews at the household unit farmers. While the secondary data obtained from the relevant authorities. Data analysis processed by descriptive qualitative, quantitative and economic analysis. The results showed that the corn plants net income around IDR.559.450,-/harvest with $B / C$ ratio of about 1.2, whereas the results of raising of Costa goat net income approximately IDR.1.810.950,-/year, or equivalent of IDR.248.550,-/month with B/C ratio of about 1.1. The amount of man power corn farming around 131.12 HOK or equivalent of IDR.1.966.800,-/year, lot of time incurred by maize farmers are turning the land and mowing, while the man power Costa goat around 2.57 HOK or equivalent of IDR 38.550,-/year, the time used by farmers to shepherd. Agricultural of waste crops on the research site such as corn waste can be used as feed for Costa goat.

(Key words: Economic analysis, Costa goat, Crop)

\section{Pendahuluan}

Indonesia terkenal sebagai negara agraris dan mempunyai areal lahan perkebunan, lahan kosong, tegalan dan lahan pertanian yang cukup luas sebagai sumber daya alam yang masih perlu digali dan dapat dimanfaatkan untuk pemenuhan kebutuhan manusia di samping untuk kebutuhan pakan ternak ruminansia (Ilham et al., 2008). Pengembangan usaha kambing di setiap wilayah pedesaan masih sangat rendah, karena terkendala pada persoalan pakan, yang hampir tidak bisa diselesaikan secara

\footnotetext{
* Korespondensi (corresponding author):

Telp. +62 81282010532

E-mail: s.rusdiana20@gmail.com
} 
tuntas oleh peternak (Husen, 2005; Syahyuti, 2012). Hal ini hanya akan bisa dicarikan jalan keluarnya, jika peternak dan semua stakeholder yang terkait berusaha menganalisis akar persoalan dan mencari solusi yang sifatnya solutif agar persoalan dapat berjalan dengan baik dalam pengusahaannya.

Syamsu et al. (2003); Rusdiana dan Ratna (2009); Yoyo et al. (2013) menyatakan bahwa kambing mampu beradaptasi pada kondisi daerah yang memiliki sumber pakan hijauan yang kurang baik, dan merupakan komponen peternakan rakyat. Saat ini populasi kambing potong di Indonesia sebanyak 17.500 ekor dan menunjukan trend positif. Saptana (2012) menyatakan bahwa, salah satu teknologi yang dipandang dapat mengatasi persoalan pakan ternak ruminansia, yaitu dengan integrasi atau penggabungan dua jenis usaha komoditi dalam suatu area tertentu dan merupakan suatu ikatan yang dapat menghasilkan keuntungan secara bersama-sama. Hal ini dapat dibuktikan dengan peningkatan keberadaan populasi kambing dan domba sebesar 4,75\%/tahun.

Jenis-jenis kambing lokal yang ada di Indonesia dan banyak dipelihara oleh peternak kecil di pedesaan adalah kambing: Kosta, Marica, Samosir, Muara, Gembrong, Peranakan Etawah dan Kacang. Fitra et al. (2009) dan Setiadi et al. (2002) menyatakan ada dua rumpun kambing yang dominan di Indonesia yakni kambing Kacang dan kambing Etawah. Dhanda et al. (2003) cit. Ginting dan Fera (2008); dan Ginting (2010) menyatakan bahwa diperkirakan jumlah bangsa kambing yang menyebar diseluruh dunia sekitar 102 jenis bangsa kambing dengan bobot hidup yang sangat beragam dari yang terkecil antara 9-12 kg/ekor sampai terbesar melebihi sekitar 100 kg/ekor.

Penyebaran kambing Kosta di sekitar Jakarta dan Propinsi Banten yaitu di Kabupaten Serang, Pendeglang, serta di wilayah Tangerang, DKI Jakarta dan sekitarnya. Pada tahun 2000-2014 jumlah peternak di Desa Sukarame Kecamatan Carita Kabupaten Pandeglang Provinsi Banten sekitar 40-45 orang. Total populasi kambing Kosta sekitar 1.000-1.500 ekor. Tahun 2014-2015 jumlah peternak kambing Kosta menurun sekitar 20-25 peternak. Jumlah kambing Kosta yang dipelihara pada tahun 2015 sebanyak 100-150 ekor. Berkurangnya kambing Kosta yang dipelihara oleh peternak dikarenakan lahan untuk penggembalaan berkurang sesuai dengan pertambahan penduduk di sekitar lingkungan. Kambing Kosta yang ada di peternak sudah tidak bisa untuk dipertahankan keberadaannya karena peternak mempunyai pekerjaan lain yaitu usaha pertanian, nelayan, dagang, dan buruh bangunan. Peternak melepas kambing Kosta untuk mencari pakan antara jam 06.00-07.00 pagi dan menjelang jam 17.00-18.00 sore. Kambing pulang sendiri ke kandang masing-masing dan ada pula yang dicari oleh pemilik kambing untuk dikandangkan.

Kambing Kosta betina selang 6-7 bulan sudah beranak kembali, sekitar umur 12 bulan kambing sudah beranak. Biasanya kambing dara beranak pertama sebanyak 1 ekor, kemudian beranak ke 2-3 kali sebanyak 2-3 ekor. Kambing Kosta yang dipelihara oleh peternak di Desa Sukarame Kecamatan Cisata Kabupaten Pandeglang Banten antara 1-3 ekor/peternak dan rerata bobot badan kambing Kosta betina dewasa antara 20-30 kg/ekor, kambing Kosta jantan dewasa antara 30-45 kg/ekor pada umur 1,5-3,9 bulan.

Sebagian besar kambing Kosta di Desa Sukarame Kecamatan Carita Kabupaten Pandeglang Banten dipelihara secara semi intensif yaitu dilepas tanpa ada pengawasan dan tambahan pakan hijauan dan dikandangkan pada malam hari.

Peternak tidak memperhitungkan kerugian yang akan terjadi bila kambing hilang dan tidak pulang. Peternak percaya bahwa kambingya akan kembali ke kandang. Kotoran dari kambing Kosta oleh peternak dijadikan sebagai pupuk untuk kesuburan lahan pertanian dan sisanya tidak dimanfaatkan. Peternak belum memperhitungkan biaya input produksi pertanian dan kambing kosta. Selama ini tujuan beternak adalah sebagai usaha sampingan, tabungan dan usaha pokoknya selain bertani yaitu berdagang, buruh tani, buruh bangunan, kerja di kota dan nelayan. Hampir semua peternak usaha pokoknya bertani dan usaha sampingannyausaha kambing Kosta, artinya peternak berperan sebagai penyedia lapangan kerja. Untuk mencapai produksi dan kualitas hasil pertanian dan hasil kambing Kosta, perlu adanya diversifikasi usaha agar peternak dapat meningkatkan pendapatan yang optimal. Tujuan lainnya yaitu terjaminnya nilai jual hasil pertanian dan hasil kambing Kosta yang tinggi sehingga peternak dapat meningkatkan taraf hidup yang lebih layak dari hasil produksi pertanian dan kambing Kosta. 
Berdasarkan uraian di atas maka penelitian ini bertujuan untuk untuk mengetahui analisis ekonomi usaha tanaman pangan dan kambing Kosta di Desa Sukarame Kecamatan Carita Kabupaten Pandeglang Banten. Pengolahan tanaman pangan dan usaha kambing Kosta, diharapkan dapat memperbaiki taraf hidup peternak disamping untuk memperluas lapangan pekerjaan masyarakat peternak.

\section{Metode Penelitian}

\section{Lokasi penelitian}

Penelitian dilakukan di Desa Sukarame Kecamatan Carita Kabupaten Pandeglang Banten dengan menggunakan metoda survey lapang, kuesioner dan wawancara langsung di lokasi penelitian pada agroekosistem yang berbasis tanaman pangan dan kambing Kosta. Data primer diperoleh dari responden peternak dan data sekunder diperoleh dari Dinas Pertanian dan Peternakan Kabupaten Pandeglang-Banten, 2013.

\section{Analisis data}

Penentuan responden secara purposive random sampling sebanyak 20 responden peternak kambing Kosta. Penelitian dilakukan pada tahun 2015. Data yang diperoleh ditabulasi dan dianalisis secara deskriptif dalam bentuk tabel (Ashari et al. 2013); (Rusdiana dan Rijanto 2014). Pengeluaran nominal/riil peternak, dan profitabilitas usaha pertanian dan usaha kambing Kosta dianalisis secara statistik deskriptif dalam bentuk rerata (mean) dengan formula sebagai berikut:

$$
\bar{X}=\frac{\sum x_{i}}{N}
$$

Keterangan:

$\bar{X}=$ Rerata tingkat pemilikan lahan pertanian, produktivitas tenaga kerja peternak, pendapatan nominal/riil hasil pertanian dan hasil kambing Kosta/tahun

$x_{i}=$ Tingkat kepemilikan lahan tanaman pangan, tingkat produktivitas tenaga kerja peternak, tingkat pendapatan nominal/riil dan tingkat pengeluaran nominal/riil dari usaha pertanian dan usaha kambing Kosta ke-i

$\sum x_{i}=$ Total luas lahan tanaman pertanian yang dimiliki peternak atau total pengeluaran nominal/riil dari pertanian dan kambing Kosta atau total profitabilitas usaha tanaman pangan dan kambing Kosta

$\mathrm{N}=$ Jumlah responden / peternak.

Untuk menghitung produktivitas tenaga kerja peternak dihitung dengan rumus sebagai berikut (Ashari et al. 2013) dan (Rusdiana et al. 2014):

$$
\vec{W}=\frac{\sum Y}{A K}
$$

Keterangan :

$\bar{W}=$ Produktivitas tenaga kerja (peternak/hari/tahun)

$\sum Y=$ Total pendapatan peternak (Rp/tahun) $\mathrm{AK}=$ Jumlah keluarga peternak (orang)

Untuk menghitung profitabilitas usaha pertanian dan usaha kambing Kosta digunakan rumus sebagai berikut:

$$
\begin{gathered}
\pi=\mathrm{R}-\mathrm{TC} \\
\pi=\mathrm{P} . \mathrm{Q}-\mathrm{TC}
\end{gathered}
$$

Keterangan:

$\pi=$ Penerimaan bersih usaha tanaman pangan dan kambing Kosta (Rp/th)

$\mathrm{TR}=$ Penerimaan kotor dari usaha kambing Kosta (Rp/th)

$\mathrm{P}=$ Harga hasil produksi pertanian $(\mathrm{Rp} / \mathrm{kg})$ dan harga kambing Kosta (Rp/ekor)

$\mathrm{Q}=$ Jumlah produksi hasil pertanian dan jumlah kambing yang dijual

$\mathrm{TC}=$ Biaya input produksi ke-i (tanaman jagung dan kambing Kosta).

$\mathrm{TC}=\sum_{i=1}^{n} T C_{i}=$ Total biaya pengeluaran usaha pertanian dan kambing Kosta.

Untuk mengukur parameter struktur biaya usaha pertanian dan struktur usaha kambing Kostra dari masing-masing usaha digunakan rumus sebagai berikut:

$$
\begin{gathered}
\mathrm{CS}_{\mathrm{i}}=\frac{T C_{i}}{\sum_{i=1}^{n} T C_{i}} \times 100 \% \\
\text { atau } \mathrm{CS}_{\mathrm{i}}=\frac{T C_{i}}{T C} \times 100 \%
\end{gathered}
$$

Keterangan :

$\mathrm{CS}_{i}=$ Pangsa biaya input ke-i

$\mathrm{TC}_{\mathrm{i}}=$ Biaya input ke-i 
$\mathrm{TC}=\sum_{i=1}^{n} T C_{i}=$ Total biaya input usaha pertanian dan usaha kambing Kosta

$\sum_{i=1}^{n} C S_{i}=100 \%$

Perhitungan analisis kelayakan usaha pertanian dan kambing Kosta menggunakan beberapa faktor yang dapat menggambarkan biaya yang dikeluarkan oleh peternak yang dihitung dalam satu tahun. Besar keuntungan yang diperoleh peternak dari hasil produksi tanaman pangan dan kambing Kosta yaitu selisih antara penerimaan dan total biaya pengeluaran, sedangkan kelayakan usaha dengan metode $\mathrm{B} / \mathrm{C}$ ratio (benefit cost ratio) (Amik dan Firmansyah, 2006).

\section{Hasil dan Pembahasan}

\section{Kepemilikan kambing Kosta}

Hampir semua peternak menjual kambing Kosta betina setelah 1-6 kali beranak walaupun dengan posisi harga kambing kosta yang murah. Kambing Kosta jantan muda dan cempe jantan banyak dijual pada umur 4-8 bulan. Jumlah kambing Kosta yang dipelihara oleh peternak dari tahun ke tahun selalu berkurang, karena peternak sering menjualnya terutama pada saat membutuhkan uang untuk biaya hidup. Tahun 2014 kepemilikan kambing kosta sebanyak 3,9 ekor/peternak dan pada tahun 2015 sebanyak 3,5 ekor/peternak atau terjadi penurunan sebesar 1,60\% (Tabel 1).

Pada umumnya pemeliharaan induk sampai umur $\pm 1-5$ tahun. Dengan demikian jumlah dan produktivitas kambing Kosta di peternak setiap tahunnya berkurang, diakibatkan cara pemeliharaannya kurang intensif. Banyak peternak yang beralih profesi usaha di bidang pertanian, dagang, buruh tani, kerja di luar daerah dan menjadi nelayan. Kambing Kosta di peternak belum menjadi tujuan utama beternak.

Nilai jual tertinggi yaitu kambing Kosta jantan dewasa sebesar Rp1.500.000,-/ekor pada tahun 2014 dan meningkat menjadi Rp1.661.000,-lekor pada tahun 2015 (Tabel 2).

\section{Penyerapan tenaga kerja}

Upah yang dibayarkan untuk tenaga kerja peternak secara tunai, harian, borongan dan mingguan, namun pada saat buruh tani membutuhkan uang tunai untuk kebutuhan

Tabel 1. Kepemilikan kambing Kosta di lokasi penelitian (the ownership of Costa goat in the location)

\begin{tabular}{|c|c|c|c|c|}
\hline \multirow{3}{*}{ Uraian } & \multicolumn{4}{|c|}{ "Jumlah kambing Kosta/peternak (total of Costa goat/farmer) $(\mathrm{n}=20)$} \\
\hline & \multicolumn{2}{|c|}{2014} & \multicolumn{2}{|c|}{2015} \\
\hline & ekor (head) & $\%$ & ekor (head) & $\%$ \\
\hline Betina dewasa (doe) & 2.00 & 51,28 & 1.90 & 54.28 \\
\hline Dara betina (young female) & 0.45 & 11,53 & 0.40 & 11.42 \\
\hline Cempe betina (kid female) & 0.40 & 10,25 & 0.25 & 7.14 \\
\hline Jantan dewasa (male) & 0.35 & 8,97 & 0.25 & 7.14 \\
\hline Jantan muda (young male) & 0.30 & 7,69 & 0.30 & 8.57 \\
\hline Cempe jantan (kid male) & 0.40 & 10,25 & 0.35 & 10.00 \\
\hline Jumlah (total) & 3.90 & 100.00 & 3.50 & 100.00 \\
\hline
\end{tabular}

Tabel 2. Harga jual kambing Kosta di lokasi penelitian (price Costa goat in the location)

\begin{tabular}{|c|c|c|c|c|c|c|}
\hline \multirow{3}{*}{$\begin{array}{l}\text { Jenis ternak } \\
\text { (type of goat) }\end{array}$} & \multicolumn{6}{|c|}{ Desa Sukarame (Sukarame village) $(n=20)$} \\
\hline & \multicolumn{3}{|c|}{2014} & \multicolumn{3}{|c|}{2015} \\
\hline & $\begin{array}{c}\text { Ekor } \\
\text { (head) }\end{array}$ & Harga (price) & $\begin{array}{l}\text { Jumlah } \\
\text { (total) }\end{array}$ & $\begin{array}{c}\text { Ekor } \\
\text { (head) }\end{array}$ & Harga (price) & $\begin{array}{l}\text { Jumlah } \\
\text { (total) }\end{array}$ \\
\hline Betina dewasa (doe) & 0.70 & 785.500 & 530.850 & 0.55 & 798.000 & 438.900 \\
\hline Betina muda (young female) & 0.55 & 546.000 & 300.300 & 0.50 & 612.000 & 306.000 \\
\hline Jantan dewasa (male) & 0.45 & 1.500 .000 & 675.000 & 0.60 & 1.651 .000 & 990.600 \\
\hline Jantan muda (young male) & 0.50 & 655.500 & 327,500 & 0.45 & 720.000 & 324.000 \\
\hline Jumlah (total) & 2.20 & - & 1.833 .650 & 2.10 & - & 2.059 .500 \\
\hline
\end{tabular}


mendadak, maka buruh tani meminjam lebih dulu ke majikannya, kemudian setelah pekerjaan selesai, maka dipotong sesuai dengan jumlah uang yang dipinjamnya. Indikasi sulitnya mencari tenaga kerja, menyebabkan peternak yang mempunyai lahan luas cenderung meminta sistem upah bulanan. Hal ini dikarenakan tenaga kerja keluarga peternak sangat sulit. Tenaga muda yang masih kuat untuk bertani banyak yang bekerja di kota sebagai tenaga kerja pabrik dan ikut nelayan di laut.

Tenaga kerja yang dicurahkan untuk mengolah lahan seluas 0,5 ha dihitung berdasarkan konversi waktu $1 \mathrm{HOK}$ atau setara dengan 7 jam kerja dan memerlukan biaya sebesar Rp15.000,-/hari, sedangkan untuk pemeliharaan kambing Kosta dengan rerata kepemilikan sebanyak 4.4 ekor biaya yang dibutuhkan sebesar Rp15.500 (Tabel 3).

Waktu kerja peternak untuk usaha tanaman jagung sebanyak 131,12 HOK dan usaha ternak kambing Kosta sebesar 2,57 HOK. Usaha pertanian melakukan aktivitas kerja relatif lebih tinggi dan lebih lama sampai pasca panen dan pemasaran (Tabel 3). Usaha kambing Kosta cenderung lebih sedikit karena cara pemeliharaannya digembalakan dan tanpa ada tambahan pakan. Waktu yang digunakan peternak kambing Kosta untuk kegiatan mengandangkan \pm 1 jam/hari yang dilakukan pada sore hari sekitar jam 17.0018.00. Biaya tenaga kerja usaha pertanian jagung sebesar Rp1.966.800,/periode/panen, pengeluaran secara riil untuk biaya tenaga kerja dari usaha kambing Kosta sebesar Rp38.550,-/tahun. Rendahnya biaya tersebut karena harga jagung sesuai dengan harga pasar, tidak memerlukan biaya tenaga kerja yang tinggi, kambing mencari pakan sendiri, dan pupuk kandang dapat digunakan untuk pupuk di lahan pertanian.

\section{Tingkat kepemilkan lahan}

Sunartomo (2015) menyatakan bahwa fenomena konversi lahan muncul seiring makin tinggi dan bertambahnya tekanan kebutuhan dari permintaan terhadap lahan baik dari sektor pertanian maupun dari sektor nonpertanian, sebagai akibat bertambahnya penduduk dan kebijakan pembangunan. Kebutuhan lahan untuk pemukian penduduk memang setiap tahunnya selalu meningkat, untuk itu perlu dilakukan pemetaan lahan produktif yang harus dipertahankan untuk kepentingan bersama demi kemakmuran masyarakat Indonesia. Lahan pertanian perlu dipertahankan secara rasional. Usaha tanaman jagung yang sering dilakukan petani di pedesaan dalam waktu tanam sekitar satu tahun 3 kali. Tingkat kepemilikan lahan dan dari sisi penggunaan lahan baik menyangkut

Tabel 3. Curahan tenaga kerja peternak kambing Kosta (man power of Costa goat)

\begin{tabular}{|c|c|c|c|c|c|}
\hline \multirow[b]{2}{*}{$\begin{array}{l}\text { Jenis pekerjaan } \\
\text { (type of job) }\end{array}$} & \multicolumn{5}{|c|}{ Usaha pertanian jagung (crop corn business) $(n=20)$} \\
\hline & $\begin{array}{l}\text { Jumlah (jam/hari) } \\
\text { (total (hour/day)) }\end{array}$ & $\begin{array}{c}\text { Rerata } \\
\text { (average) }\end{array}$ & $\begin{array}{l}\text { Jam tahun } \\
\text { (hour/year) }\end{array}$ & $\begin{array}{c}\text { HOK } \\
\text { (man } \\
\text { power/day) }\end{array}$ & $\begin{array}{c}\text { Rp/thn } \\
\text { (IDR/year) } \\
\text { (IDR 15.000) }\end{array}$ \\
\hline Penanaman (planting) & 4 & 0.20 & $72 / 7$ & 10.28 & 153.450 \\
\hline Pemupukan (fertilization) & 6 & 0.30 & $108 / 7$ & 15.42 & 231.428 \\
\hline Pembersihan (mowing) & 15 & 0.75 & $270 / 7$ & 38.57 & 578.550 \\
\hline Peyemprotan (spraying) & 14 & 0.70 & $252 / 7$ & 36.00 & 540.000 \\
\hline Pemanenen (harvesting) & 12 & 0.60 & $216 / 7$ & 30.85 & 462.750 \\
\hline Jumlah (total) & 51 & 2.55 & $918 / 7$ & 131.12 & 1.966 .800 \\
\hline \multirow[b]{2}{*}{$\begin{array}{l}\text { Jenis pekerjaan } \\
\text { (type of job) }\end{array}$} & \multicolumn{5}{|c|}{ Usaha kambing Kosta (Costa goat business) $(\mathrm{n}=20)$} \\
\hline & $\begin{array}{l}\text { Jumlah (jam/hari) } \\
\text { (total (hour/day)) }\end{array}$ & $\begin{array}{c}\text { Rerata } \\
\text { (average) }\end{array}$ & $\begin{array}{l}\text { Jam tahun } \\
\text { (hour/year) }\end{array}$ & $\begin{array}{c}\text { HOK } \\
\text { (man } \\
\text { power/day) }\end{array}$ & $\begin{array}{c}\text { Rp/thn } \\
\text { (IDR/year) } \\
\text { (IDR 7.500) }\end{array}$ \\
\hline Digembalakan (herded) & - & - & - & - & - \\
\hline Mencari rumput (looking for feed) & - & - & - & - & - \\
\hline $\begin{array}{l}\text { Perawatan ternak (maintenance of } \\
\text { goat) }\end{array}$ & - & - & - & - & - \\
\hline Mengandangkan (in the cage) & 1 & 0.05 & $18 / 7$ & 2.57 & 38.550 \\
\hline Jumlah (total) & 1 & 0.05 & $18 / 7$ & 2.57 & 38.550 \\
\hline
\end{tabular}


status penguasaan lahan milik sendiri, bukan milik sendiri menyewa, menggadai maupun lainnya mengalami perubahan. Demikian juga lahan milik sendiri, baik yang digarap sendiri maupun digarap oleh orang lain, baik dengan cara disewakan, disakapkan, digadaikan maupun lainnya, juga tidak banyak berubah.

\section{Analisis kelayakan usaha tanaman jagung}

Tanaman jagung merupakan tanaman pangan yang banyak diusahakan oleh petani di setiap wilayah di Indonesia. Untuk meningkatkan produksi jagung dapat ditempuh dengan beberapa metoda penanaman di antaranya perluasan penanaman jagung, penerapan inovasi teknologi terbaru seperti adopsi benih unggul, pengendalian penyakit dan perbaikan budidaya cara penanaman di lapangan. Istiqomah et al. (2012) cit. Andri (2014) menyatakan bahwa untuk kegiatan peningkatan produktivitas dan perluasan produksi dapat dilakukan melalui kegiatan pendampingan secara langsung kepada petani, seperti program SLPTT yang telah dilaksanakan di daerah Jawa Timur, Bojonegoro. Rohaeni et al. (2006) menyatakan bahwa dengan menggunakan pupuk kandang dari kotoran sapi dan kambing dapat memperbaiki sifat fisik dan kimia tanah.

Usaha tanaman jagung yang dilakukan oleh peternak di Desa Sukarame Kecamatan Carita Kabupaten Pandeglang Provinsi Banten, cara melakukan penanamannya tidak melihat musim, usaha tanaman jagung menggunakan lahan sebesar 0,5 ha atau sebesar $5.000 \mathrm{~m}^{2}$, terlihat pada Tabel 5 .

Tabel 5 menunjukkan bahwa, keuntungan bersih dari usaha tanaman jagung sebesar Rp559.450,-/panen dengan $\mathrm{B} / \mathrm{C}$ ratio 1,2 . Tanaman jagung dipanen umur 3 bulan dengan produksi sebanyak $775 \mathrm{~kg}$ dengan asumsi harga jagung yang berlaku saat ini di peternak sebesar Rp4.300,-/kg

Tabel 4. Kepemilikan lahan (land ownership)

\begin{tabular}{lccccc}
\hline \hline $\begin{array}{c}\text { Jenis kepemilikan } \\
\text { (type of ownership) }\end{array}$ & $\begin{array}{c}\text { Lahan kosong } \\
\text { (nonproductive land) }\end{array}$ & $\begin{array}{c}\text { Sawah } \\
\text { (field) }\end{array}$ & $\begin{array}{c}\text { Kebun } \\
\text { (dry land) }\end{array}$ & $\begin{array}{c}\text { Pekarangan } \\
\text { (yard) }\end{array}$ & Total \\
\hline Milik sendiri (owner) & 0,40 & 0,47 & 0,41 & 0,33 & 1,61 \\
Menyewa (hire) & 0.00 & 0,23 & 0,26 & 0.00 & 0,49 \\
Digarap/diolah (treated) & 0.00 & 0,44 & 0,18 & 0.00 & 0,62 \\
Digadaikan (mortgaged) & 0.00 & 0,24 & 0,22 & 0.00 & 0,46 \\
Tidak digarap (non productive) & 0.00 & 0.00 & 0,02 & 0.00 & 0,02 \\
\hline
\end{tabular}

Tabel 5. Analisis ekonomi usaha tanaman jagung seluas 0,5 ha (the economic analysis of business corn crop of $0.5 \mathrm{ha}$ )

\begin{tabular}{|c|c|c|c|}
\hline Uraian & Volume & $\begin{array}{l}\text { Nilai (Rp) } \\
\text { (value }(R p) \text { ) }\end{array}$ & $\begin{array}{c}\text { Jumlah (Rp) } \\
\text { (total/Rp)) }\end{array}$ \\
\hline \multicolumn{4}{|l|}{ Biaya produksi /(input) (cost of production) } \\
\hline - Bibit jagung (corn seed) & $6 \mathrm{~kg}$ & 25.000 & 150.000 \\
\hline - Urea & 2 zak & 200.000 & 200.000 \\
\hline$-\mathrm{HCL}$ & $1,5 \mathrm{zak}$ & 100.000 & 150.000 \\
\hline - Pupuk kandang ayam (chicken manure) & $500 \mathrm{~kg}$ & 280 & 140.000 \\
\hline - Pupuk kandang kambing/domba (goat/sheep manure) & $500 \mathrm{~kg}$ & 320 & 160.000 \\
\hline $\begin{array}{l}\text { - Insektisida/herbisida } \\
\text { - Tenaga kerja, mengolah tanah, menanam, membersihkan } \\
\text { rumput, pemupukan penyemprotan, penyulaman, panen } \\
\text { (labor to tilling the soil, planting, weeding, fertilizing, spraying, } \\
\text { replanting, harvesting). }\end{array}$ & $\begin{array}{l}2 \text { liter } \\
131.12\end{array}$ & $\begin{array}{l}30.000 \\
15.000\end{array}$ & $\begin{array}{r}60.000 \\
1.966 .800\end{array}$ \\
\hline Jumlah input (total input) & & & 2.826 .800 \\
\hline \multicolumn{4}{|l|}{ Pendapatan/output (income) } \\
\hline - Hasil produksi jagung (yield of corn) & $787.5 \mathrm{~kg}$ & 4.300 & 3.386 .250 \\
\hline - Pendapatan bersih/panen (net income/harvest) & & & 559.450 \\
\hline$-B / C$ & & & 1.2 \\
\hline
\end{tabular}


diambil langsung dari kebun. Tenaga kerja peternak dibutuhkan sebanyak 131,12 HOK dengan upah tenaga kerja sebesar Rp15.000,-/hari.

\section{Analisis kelayakan usaha kambing Kosta}

Dalam analisis ekonomi usaha pemeliharaan kambing pada dasarnya merupakan kegiatan utama bagi peternak di pedesaan, di mana hasil produksi sepenuhnya diarahkan ke pasar, dan jarang sekali ditemui peternak langsung mengkonsumsi sendiri hasil usaha ternak yang dipelihara atau hasil dibudidaya sendiri (Winarso, 2010). Bila dilhat dari produk utama yang dihasilkan berupa daging, maka untuk menghadapi pasar peran kambing sebagai supplier diharapkan dapat bersubstitusi dengan daging sapi, kerbau, dan domba. Skala usaha yang menguntungkan pada dasarnya adalah semakin banyak kambing yang dipelihara akan semakin efisien dan efektif.

Hasil penelitian Rusdiana dan Ratna (2009) menyebutkan usaha pemeliharaan kambing di pedesaan dengan kontribusi tanaman ubi kayu dengan perhitungan yang sederhana, peternak mendapatkan keuntungan yang optimal. Analisis ekonomi dari usaha kambing Kosta pada penelitian ini berdasarkan perhitungan skala 3 ekor kambing Kosta terdiri dari 2 ekor betina induk dan 1 ekor jantan. Kandang kambing Kosta terbuat dari kayu, bambu, dan genteng dan diperkirakan nilai pembuatan kandang sebesar Rp800.000/unit dengan kapasitas tampung sebanyak 6-10 ekor untuk kambing dewasa, muda dan anak, dengan ukuran kandang 1,5 × $3 \mathrm{~m}^{2}$.

Tabel 6 menunjukkan bahwa, usaha kambing Kosta dengan skala 2,1 ekor/peternak mendapatkan keuntungan bersih sebesar Rp1.810.950,-/tahun, atau setara Rp248.550,-/bulan dengan B/C ratio 1,2. Biaya modal awal untuk pembelian bibit kambing Kosta dapat ditutup dari hasil penjualan pembesaran anak kambing Kosta.

Asumsi lainnya bahwa, tingginya harga kambing Kosta dapat dipengaruhi oleh kondisi tubuh kambing Kosta betina berdasarkan

Tabel 6. Analisis ekonomi usaha kambing Kosta

(the economic analysis of business Costa goat)

\begin{tabular}{|c|c|c|c|}
\hline Uraian & Volume & $\begin{array}{c}\text { Rerata } \\
\text { harga/Rp } \\
\text { (average } \\
\text { cost/Rp) }\end{array}$ & $\begin{array}{l}\text { Jumlah } \\
\text { (total) }\end{array}$ \\
\hline \multicolumn{4}{|l|}{ Biaya tetap (fixed cost) } \\
\hline \multicolumn{4}{|l|}{ A. Biaya investasi dan penyusutan (investment and depreciation cost) } \\
\hline 1. Kandang (unit) (cage (unit)) & 1 unit & 800.000 & 800.000 \\
\hline $\begin{array}{l}\text { 2. Penyusutan kandang } / 5 \text { tahun (depreciation cage every } 5 \\
\text { years) }\end{array}$ & - & - & 160.000 \\
\hline 3. Peralatan kandang (paket) (equipment) & 1 paket & 30.000 & 30.000 \\
\hline Jumlah $(2+3)($ total) & - & - & 190.000 \\
\hline \multicolumn{4}{|l|}{ B. Biaya variable (variable cost) } \\
\hline - Tenaga kerja keluarga (HOK) (family labor) & 2.57 & 15.000 & 38.550 \\
\hline - Pakan konsentrat (concentrate feed) & - & 20000 & 20000 \\
\hline Total $(A+B)$ & - & - & 248.550 \\
\hline \multicolumn{4}{|l|}{ C. Nilai jual ternak kambing Kosta (selling price) } \\
\hline - Betina dewasa $($ doe $)$ & 0.55 & 798.000 & 438.900 \\
\hline - Betina muda (young female) & 0.5 & 612.000 & 306.000 \\
\hline - Jantan dewasa (male) & 0.6 & 1.651 .000 & 990.000 \\
\hline - Jantan muda (young male) & 0.45 & 720.000 & 324.000 \\
\hline $\begin{array}{l}\text { Jumlah (total) } \\
\text { Pendapatan kotor/tahun (gross income/year) }\end{array}$ & 2.1 & - & $\begin{array}{l}2.059 .500 \\
2.059 .500\end{array}$ \\
\hline Pendapatan bersih/tahun (net income/year) & & & 1.810 .950 \\
\hline Pendapatan bersih/bulan (net income/month) & & & 248.550 \\
\hline $\mathrm{B} / \mathrm{C}$ & & & 1.2 \\
\hline
\end{tabular}


keturunan induk yang baik. Rusdiana dan Rijato (2014) menyatakan bahwa peternak mendapatkan keuntungan riil apabila memelihara kambing betina induk atau betina produktif paling sedikit antara 5-10 ekor.

$$
\text { Peternak akan mendapatkan }
$$
keuntungan secara riil sebesar $100 \%$ dari hasil penjualan anak yang dibesarkan secara optima apabila usahanya terkonsentrasi pada kambing Kosta. Pemeliharaan kambing Kosta layak untuk dapat dipertahankan dan dikembangkan karena biaya yang dikeluarkan untuk usaha kambing Kosta lebih banyak pada biaya tenaga kerja dan pembelian bibit. Untuk biaya pakan hijauan diasumsikan ke dalam biaya tenaga kerja peternak itu sendiri. Pendapatan peternak tahun 2014 dan 2015 sebesar Rp1.833.650,-/tahun dan Rp2.059.500,-/tahun atau terdapat peningkatan sebesar 1,3\%, dimana kontribusi terbesar berasal dari hasil penjualan betina induk dan jantan dewasa. Berdasarkan data dan informasi dari peternak, kambing Kosta didominasi oleh kelahiran kembar dan tunggal yaitu jantan, betina, betina-betina, jantanjantan, dan jantan-betina. Untuk itu usaha kambing Kosta perlu dipertahankan karena kelahirannya cukup baik. Kambing Kosta pada kelahiran kembar biasanya anak jantan cukup besar dan betina cukup kecil, sedangkan pada kelahiran tunggal baik jantan maupun betina pada saat lahir cukup besar.

\section{Kesimpulan}

Usaha tanaman jagung mendapatkan keuntungan bersih sebesar Rp559.450,/panen dan $\mathrm{B} / \mathrm{C}$ ratio setara 1,2 , sedangkan hasil dari usaha kambing Kosta sebesar Rp1.810.950,-/tahun, atau setara Rp248.550,-/bulan dengan B/C ratio setara 1,1. Besarnya penyerapan tenaga kerja keluarga untuk pertanian jagung sebesar 131,12 HOK atau setara Rp1.966.800/tahun. Waktu yang dikeluarkan oleh peternak adalah mengolah lahan, membersihkan rumput. Tenaga kerja peternak kambing Kosta adalah sebesar 2,57 HOK atau setara Rp38.550,/tahun. Penggunaan lahan untuk usaha tanaman jagung sebenarnya tidak harus menggunakan lahan yang cukup luas.

\section{Daftar Pustaka}

Amik, K. dan M. A. Firmansyah. 2006. Kajian teknologi usahatani jagung dilahan kering Kalimantan Selatan. Pusat Penelitian dan Pengembangan Sosial
Ekonomi Pertanian, Badan Litbang Pertanian. Jurnal Pengkajian dan Pengembangan Teknologi Pertanian 8: 39-54.

Ashari, A. Ening, S. Yana, C. R. Adawiyah dan S. Suharyono. 2013. Kajian efektivitas sistem resi gudang dalam stabilisasi pendapatan petani. Laporan Kegiatan Kajian Isu-Isu Aktual Kebijakan Pembangunan Pertanian 2013. Pusat Sosial Ekonomi dan Kebijakan Pertanian, Kementerian Pertanian, Desember 2013.

Andri, B. K. 2014. Profil dan karakteristik sosal ekonomi petani tanaman pangan di Bojonegoro. Agriekonomika Jurnal Penelitian Sosial Ekonomi dan Kebijakan Pertanian 3: 166-179.

Dinas Pertanian dan Peternakan Kabupaten Pandeglang-Banten. 2013. Laporan Tahun 2013 Perubahan data pada akhir Desember 2013.

Fitra, A. P., B. Aron, M. Doloksaribu, dan S. Erwin. 2009. Petunjuk Teknis Potensi Plasma Nutfah Kambing Lokal Indonesia. Buku. Loka Penelitian Kambing Potong. Badan Litbang Pertanian, Jakarta.

Ginting, P. S. dan M. Fera. 2008. Kambing, Boerka: kambing tipe pedaging hasil persilangan Boer x Kacang. Wartazoa Buletin Ilmu Peternakan Indonesia 18: 115-126.

Ginting, P. 2010. Beberapa alternatif skema percepatan perkembangan dan penyebaran bibit kambing boerke. Prosiding Seminar Nasional Membangun Sistem Inovasi di Perdesaan. Balai Besar Pengkajian dan Pengembangan Teknologi Pertanian Bogor, 15-16 Oktober 2009.

Husen, H. 2005. Evaluasi pemanfaatan sumberdaya lahan di antara kelapa dengan tanaman sela berdasarkan kajian aspek sosial ekonomi dan konservasi. Jurnal Pengkajian dan Pengembangan Teknologi Pertanian 8: 111-123.

Ilham, N., S. Hermanto, dan D. S. Priyarsono. 2008. Efektivitas kebijakan harga pangan terhadap ketahanan pangan. Jurnal Agro Ekonomi, Pusat Analisis Ekonomi dan Kebijakan Pertanian 24: 157-177.

Rohaeni, E. Siti, N. Amali, Saumanto, A. Darmawan, dan A. Sabban. 2006. Pengkajian integrasi usahatani jagung dan ternak sapi di lahan kering 
Kabupaten Tanah Laut Kalimantan Selatan. Jurnal Pengkajian dan Pengembangan Teknologi Pertanian 9: 129-139.

Rusdiana, S. dan A. S. Ratna. 2009. Kontribusi tanaman ubi kayu dan ternak kambing terhadap pendapatan petani: Analisis ekonomi (Kasus di Kota Bogor). Prosiding Seminar Nasional Teknologi Peternakan dan Veteriner. Kementerian Pertanian, Bogor 13-14 Agustus 2010.

Rusdiana, S., I. G. M. Budiarsana, dan Sumanto. 2014. Analisis pendapatan usaha pertanian dan peternakan kerbau di Kabupaten Lombok Barat Nusat Tenggara Barat (NTB). Jurnal Ekonomi Pertanian 1: 56-67.

Rusdiana, S. dan H. Rijanto. 2014. Pemanfaatan hijauan pakan ternak Btachiaria ruzizienis dan Stylosanthes gaianenis mendukung usaha ternak kambing di Kabupaten Asahan. SEPA. Jurnal Sosial Ekonomi Pertanian dan Agribisnis10: 247-256.

Syamsu, J. A., A. Lilya, K. Sopiyan, E. Mudikdjo, dan S. Gumilar. 2003. Daya dukung limbah pertanian sebagai sumber pakan ternak ruminansia di Indonesia. Jurnal Wartazoa 13: 32-37.

Syahyuti. 2012. Pengorganisasian secara personal dan gejala individualisasi organisasi sebagai karakter utama pengorganisasian diri petani di Indonesia. Jurnal Forum Agro Ekonomi 30: 129-145.
Saptana. 2012. Konsep efisiensi usahatani pangan dan implikasinya bagi peningkatan produktivitas. Jurnal Forum Agro Ekonomi 30: 109-128.

Setiadi, B., B. Tiesnamurti, Subandriyo, T. Sartika, U. Adiati, D. Yulistiyani, dan I. Sendow. 2002. Koleksi dan evaluasi karakteristik kambing kosta dan gembrong secara ex-situ. Laporan Hasil Penelitian APBN 2001. Balai Penelitian Ternak Ciawi, Bogor.

Sunartomo, A. F. 2015. Perkembangan konversi lahan pertanian di Kabupaten Jember. Jurnal Agriekonomika 4: 2236.

Yoyo, S. Mochamad, dan P. Agus. 2013. Analisis potensi peternak dalam pengembangan ekonomi usaha kambing lokal di Kabupaten Banyumas. Jurnal IImiah Peternakan 1: 619-626.

Winarso, B. 2010. Prospek dan kendala pengembangan agribisnis ternak kambing dan domba di Indonesia. Prosiding Seminar Nasional Peningkatan Daya Saing Agribisnis Berorientasi Kesejahteraan Petani, Pusat Analisis Ekonomi dan Kebijakan Pertanian Bogor, Kementerian Pertanian Bogor, Maret 2009. 